\title{
Retreat availability and social influences on retreat sharing in group-living huntsman spiders, Delena lapidicola and Delena cancerides (Araneae: Sparassidae)
}

\author{
Cameron Jones ${ }^{1,2}$ and Linda S. Rayor ${ }^{1}$ : ${ }^{1}$ Department of Entomology, Cornell University, Ithaca, NY 14853; \\ ${ }^{2}$ Department of Neurobiology, Physiology and Behavior, Animal Behavior Graduate Group, University of California, \\ One Shields Avenue, Davis, CA 95616; E-mail: LSR1@cornell.edu
}

\begin{abstract}
Retreat selection is critical for animals that spend much of their diel cycle in retreats. At issue is how retreat availability and social dynamics interact to influence whether retreats are defended from or shared with conspecifics. The prolonged subsocial huntsman spider, Delena lapidicola (Hirst 1991, Sparassidae), lives in family groups under rock retreats which are relatively abundant on granite headlands in Western Australia. Their more social congener, $D$. cancerides (Walckenaer, 1837), lives in rare retreats under the bark of trees in southern Australia. We tested retreat sharing patterns with kin and non-kin in D. lapidicola, and of unrelated adult female $D$. cancerides using laboratory assays. For each trial, two spiders were introduced 12-hr apart in a large arena with two retreats and given 24-hr to share a retreat or occupy their own retreat. Aggression and mortality were recorded. In this study, $42 \%$ of D. lapidicola shared retreats regardless of kinship, age, sex, mass or natal colony. Even adult females shared retreats peacefully. Aggression only occurred once. In stark contrast, no D. cancerides adult females shared retreats and $36 \%$ of the trials resulted in mortality or serious injury. Our results support the hypothesis that an abundance of retreats in D. lapidicola habitats reduces pressure to defend and allows sharing with little discrimination of kinship, while the rarity of retreats in $D$. cancerides habitats results in aggressive defense.
\end{abstract}

Keywords: Retreat site selection, saxicolous ectotherm, kin recognition, habitat saturation, sociality

Many animals spend long portions of their day hidden in diurnal or nocturnal retreats. These retreats are critical, valuable resources that impact all aspects of an organism's fitness, as the retreats provide protection from a wide array of abiotic and biotic selective forces (Berryman \& Hawkins 2006). Abiotic forces include temperature, humidity, and wind, while biotic forces include dynamics such as intraspecific attraction or competition, interspecific competition, or predation risk (Langkilde \& Shine 2004; Croak et al. 2008). These forces are particularly salient to animals that live on open rock outcrops where vegetation does not provide a buffer for abiotic forces, and where competition for a limited number of available retreats under rocks can be intense (Langkilde \& Shine 2004). Evidence suggests that saxicolous (or rockdwelling) ectotherms such as spiders, lizards, and snakes are extremely particular in their choice of retreat site selection, clearly preferring certain thermal, spatial, and other microclimate features of the specific rock retreats (Huey et al. 1989; Goldsbrough et al. 2004; Croak et al. 2008), as well as where the retreat is positioned in the overall landscape (Croak et al. 2012).

Social dynamics and retreat availability interact to determine whether rock retreats are defended or shared with conspecifics in group-living, saxicolous animals (Pike et al. 2011). Intersecting factors likely influence decisions to share retreats. (1) Individuals may compete for optimal retreats and expend energy to maintain solo occupancy of that retreat, particularly if suitable retreats are rare. (2) Relatively abundant retreats may mean that individual retreats are temporarily shared because they are not worth defending. (3) Relatively abundant retreats may mean that individuals never need to share retreats. (4) There are benefits to sharing retreats even when they are relatively abundant. (5) In social species, individuals tolerate retreat sharing with other conspecifics, but whether there are preferences for kin or for specific age-sex classes may vary with the species.

In a laboratory study, we explored which of these situations best describes the retreat sharing behavior of a nocturnally active, exclusively saxicolous prolonged subsocial spider, Delena lapidicola (Hirst, 1991) (previously, Eodelena lapidicola; see Agnarsson \& Rayor 2013). In this group-living spider species, potential retreats are relatively abundant in the wild (Rayor 2016). Our goal was to determine whether the spiders would defend or share retreats with conspecifics, and whether there were behavioral differences in retreat sharing between non-kin and among various age-classes. As a contrast, we compared patterns of retreat sharing in the same experimental design with its more social sister species, Delena cancerides (Walckenaer, 1837), which lives under the bark of trees in retreats which are exceedingly rare (Yip et al. 2012), and which have been demonstrated to discriminate who share their retreats based on kinship and the age-class of the conspecifics (Yip et al. 2009). All evidence indicates that retreat sharing in $D$. cancerides is best described as a situation where individuals actively compete to maintain occupancy of rare retreats but readily share retreats with kin or colony mates and younger animals (Yip et al. 2009; Yip \& Rayor 2011; Rayor 2016).

Delena lapidicola live in crevices under exfoliated rocks exclusively on granite headlands in SW Western Australia (Agnarsson \& Rayor 2013). The nocturnally active spiders remain under the rock retreats during the day, foraging at night from the edge of the rock or in the open. Although potential retreats appear plentiful, quantitative analysis demonstrates that there are clear preferences for rocks of certain sizes, composition, crevice size, and thermal properties, which may reduce the actual number of potential retreats (Rayor, van den Berg, and Hurst, unpublished data). Recent discoveries suggest these spiders live in matrilineal family groups with up to three cohorts of siblings remaining under 
the rock retreat with their mother (Rayor 2016). Offspring remain with their mothers under the natal rock until at least the $5^{\text {th }}$ or $7^{\text {th }}$ instar out of 10 or 11 instars. Patchily distributed colonies of $D$. lapidicola are often found in 'neighborhoods', where occupied retreats are within $\sim 10 \mathrm{~m}$ of one another. A particularly dense neighborhood may include several retreats occupied by an adult female with her offspring, several male:female pairs, and mature, penultimate, or (rarely) $5^{\text {th }}$ or $6^{\text {th }}$ instar solitary individuals. Within this area, spiders without young may move between retreats. Therefore it is probable that (1) individuals from different colonies interacted on occasion while foraging at night or visited each other's rock retreats to assess the age, sex, receptivity, or holding power of the resident, and (2) that at least some of the neighboring colonies were occupied by kin who had spread outward from their natal colony. These expectations are supported by evidence from extensive studies on reptiles, particularly velvet geckos (Oedura lesueurii: Gekkonidae) and, to a lesser extent, broad-headed snakes (Hoplocephalus bungaroides: Elapidae) which live exclusively on rock outcrops. These species largely remain in their natal area and do not move widely between rocky outcrops (Dubey et al. 2011, 2012).

Social factors and kin recognition may also affect retreat sharing. In the subsocial and prolonged subsocial spider species where a single female remains in association with her offspring for prolonged periods (see Yip \& Rayor 2014), there is increasing evidence that many of these species exhibit kin or colony mate discrimination, are resistant to accepting non-kin into their webs or retreats, and are less likely to share prey with those individuals (Evans 1999; Bilde \& Lubin 2001; Beavis et al. 2007; Schneider \& Bilde 2008; Yip et al. 2009; Grinsted et al. 2011; Ruch et al. 2015). Compared to the more social cooperative and colonial social spider species which remain in their natal colony and show little evidence of nepotism, these subsocial species are more likely to encounter non-kin and to live in smaller groups where there may be greater costs to accepting non-kin into groups (Auletta \& Rayor 2011; Berger-Tal et al. 2015). This appears to be particularly true of the prolonged subsocial huntsman species which, instead of constructing webs, must search for retreats of limited size and availability (Yip et al. 2012; Rayor 2016). These small discrete retreat sites may increase both intraspecific competition for occupancy of the retreats and the benefits of discriminating kin from non-kin (Yip et al. 2009, 2012).

Based on previous experiments on $D$. cancerides, we hypothesized that when given the choice of sharing or choosing an empty retreat, $D$. lapidicola would aggregate with kin from the same colony, younger animals, or the opposite sex, but prefer to be alone in a retreat if the introduced animal did not fit these criteria. We hypothesized that adult or penultimate females would be extremely unlikely to share retreats, and, if they shared, they would do so only with colony mates. Additionally, we predicted that aggression, possibly leading to mortality, would be higher between older animals and non-kin. These two predictions fit with previous studies on their sister group, D. cancerides, which aggressively defend retreats from potential reproductive competitors (Yip et al. 2009; Yip \& Rayor 2011). Similarly, we hypothesized that spiders whose natal colonies in the wild were closer together were more likely to be related than individuals from colonies found great distances from one another, and that spiders from proximate colonies might share retreats more frequently. To directly compare the patterns of retreat sharing and aggression found in $D$. lapidicola with $D$. cancerides, we used the same experimental protocol to determine rates of retreat sharing and aggressive interactions between unrelated penultimate and adult female $D$. cancerides. This allowed us to examine how retreat sharing behavior differs between two species where the potential costs associated with accepting non-colony mates is similar, but the abundance of suitable retreats in their native habitat is markedly different.

\section{METHODS}

Study organisms.-In 2014, D. lapidicola [Sparassidae: Deleninae] were collected from under exfoliated rocks in granite headlands along the southern coast of Two People's Bay National Park, Western Australia, Australia. Colony demographics were noted and location of sites recorded on GIS. Prior to the start of experiments, individuals were maintained in family groups or mated pairs at Cornell University, New York, USA, in covered glass arenas $(45 \times$ $35 \times 30 \mathrm{~cm}$ tall) under light:dark $18: 6$ cycles at $23^{\circ} \mathrm{C}$. Spiders were given water and fed house crickets, Acheta domesticus, ad libitum. Delena lapidicola used in this study included adult females and subadults (between $7^{\text {th }}$ to $9^{\text {th }}$ instar, where adults are the $10^{\text {th }}$ instar.) The second huntsman species, $D$. cancerides, was collected from Canberra, ACT, Australia in 2014. Prior to experiments, individual adult female $D$. cancerides were housed in $41 \times 20 \times 26 \mathrm{~cm}$ glass terrariums with artificial bark (Plexiglas sheets each attached with Velcro) providing $\sim 1 \mathrm{~cm}$ deep retreats along the long sides of the arena (see Yip et al. 2009 for details).

Retreat size preference.-In the field, D. lapidicola use horizontally-oriented retreats under rocks that have an average area of $\sim 8 \mathrm{~cm}^{2}$ with $\sim 1 \mathrm{~cm}$ crevice entrances (Rayor, van den Berg, \& Hurst, unpublished data). To test preferences for rock retreat size in the lab, rock retreats of two different sizes were placed at each end of a large terrarium $(91 \times 45 \times 40$ $\mathrm{cm}$ ) and a water dish was placed equidistant from the two potential retreats. Retreats were made with commercial $9.5 \times$ $20 \mathrm{~cm}$ ceramic tiles placed on top of each other with a front crevice of $\sim 1 \mathrm{~cm}$ and back of the tiles touching. Rock widths were divided into three categories: small $(9.5 \times 20 \mathrm{~cm})$, medium $(19 \times 20 \mathrm{~cm})$ or large $(28.5 \times 20 \mathrm{~cm})$. Preliminary tests revealed that spiders always moved into a retreat during the experiment, and would occupy all three rock sizes in the absence of an alternative retreat. Preference tests were conducted between different sizes of rock retreats: small vs. medium $(n=10)$, small vs. large $(n=10)$, and medium vs. large $(n=18)$. One $D$. lapidicola spider was used per preference trial and each individual was tested only once. We recorded the sex, mass, carapace width, length of femur of the second leg and length of the tibia and tarsus of the second leg. Spiders were introduced in front of the water dish in late afternoon, and left overnight to allow them to adjust to the arena and choose a rock retreat. After $\sim 12$ hours, the location of the spider and the rock size was recorded. After each trial, the terrarium, water dish, and rocks were thoroughly washed with warm water. Tiles that were reused were randomly paired with other tiles and placed in switched positions. 
Social interaction trials. - We added two individuals to the arena on subsequent days and allowed them to remain together overnight to assess whether the choice to join another animal in one retreat or to choose a solo retreat was based on the individual D. lapidicola's colony, age, or sex, Retreat sizes that were favored in the rock size preference trials were used in the social interaction trials. Each trial consisted of two retreats of the same size placed at opposite ends of a covered glass arena with dimensions $(91 \times 45 \times 40 \mathrm{~cm})$ with a water dish equidistant between the two retreats. One pair of $D$. lapidicola was used per trial and consisted of either individuals from different colonies or from the same colony. The first specimen of each trial ("Resident") was lightly anesthetized with $\mathrm{CO}_{2}$, marked with Testors enamel paint, and its sex, mass, carapace width, length of femur of the second leg and length of the tibia and tarsus of the second leg was recorded. These measurements were used to infer instar of each individual. Due to the strong correlation between these measurements within $D$. lapidicola, we will henceforth refer to mass as the size of each specimen. The resident was then placed within the testing arena in front of the water dish and given $>12$ hours to occupy a retreat. On the second day, a second specimen ("Introduced") of similar size from either the same or different colony was similarly marked and measured before being placed in the arena. Differences in size between the resident and introduced species were minimal $(\mathrm{X} \pm \mathrm{SE}=0.52 \pm 0.06$ $\mathrm{cm})$. The arena was monitored for $10 \mathrm{~min}$ following the introduction of the introduced specimen to record any signs of aggression, before the two spiders were left overnight for $>12$ hours. In all 48 trials, spiders had moved into a retreat overnight. We recorded which retreat the resident and introduced spiders were in, along with any evidence of aggressive encounters (injury to a spider, missing legs, or death). Due to the limited availability of $D$. lapidicola for these experiments, some individuals were used several times but always in different permutations: Adult females from separate colonies $n=12$, trials $n=18$; Subadults from separate colonies $n=39$, trials $n=20$; Subadults from the same colonies $n=19$, trials $n=10$. No individual was used more than twice in different pairs after a minimum period of 48 hours post trial and any individuals injured during a trial were removed from the rest of the study. Pair composition and determination of which individual was used as "Resident" or "Introduced" was random. After each trial, the arena, rocks and water dishes were washed and replaced.

For comparison, we analyzed the behavior of 15 adult female $D$. cancerides from different colonies in 30 introduction trials to assess the propensity to share retreats and relative aggression. Individuals were retested several times, but they were always in different permutations and injured spiders were never retested. Only large retreats were used and, because this species is less dorso-ventrally flattened than $D$. lapidicola, the crevice size was doubled. Although $D$. cancerides primarily use retreats under bark, they readily occupy retreats under rocks, roofs, or shutters if other retreats are unavailable.

Colony separation distance.-To evaluate the possibility that spiders either remembered individuals from neighboring colonies or that colony mates or kin were distinguishable by olfactory cues on their cuticle (Grinsted et al. 2011), we calculated the distances between the capture sites of the
Table 1.-Factors determining propensity of $D$. lapidicola to share retreats (48 trials on 70 individuals).

\begin{tabular}{lcccc}
\hline Random effects & Variance & LRT & & $P$ \\
\hline ID & 0.029 & 0.006 & & 0.938 \\
Fixed effects & $\mathrm{B}$ & $\mathrm{SE}$ & $z$ & $P$ \\
Intercept & 0.244 & 0.619 & 0.395 & 0.693 \\
Same region & -0.652 & 0.862 & -0.757 & 0.449 \\
Colony & -0.262 & 0.891 & -0.294 & 0.767 \\
Female & -0.103 & 0.516 & -0.200 & 0.842 \\
Adult & -1.094 & 0.649 & -1.672 & 0.095 \\
Distance & -0.131 & 0.394 & -0.332 & 0.740 \\
Mass & 0.391 & 0.295 & 1.322 & 0.186 \\
Large Rock & 0.157 & 0.579 & 0.271 & 0.786 \\
Initial Rock left & 0.076 & 0.491 & 0.154 & 0.877 \\
Marginal R & 0.085 & & & \\
Conditional R & 0.093 & & & \\
AIC & 142.6 & & & \\
Deviance & 122.6 & & & \\
Residual df & 86 & & & \\
\hline
\end{tabular}

individual's natal retreat in the wild. We predicted that $D$. lapidicola spiders collected from neighboring colonies were more likely to be more closely related than spiders living significantly greater distances apart or from entirely separate granite headlands. Therefore to assess whether the colony distance at which the spiders had been collected had any effect on propensity to aggregate, we measured the distance between natal colonies of each spider. In this study, individuals from 21 different colonies ranging from 4 to 710 meters apart with an average distance of 286 meters were used. GPS coordinates for each of these colonies were obtained by Rayor, van den Berg, \& Hurst (unpublished data). Distances between colonies were measured between them using Google Earth (Google Inc).

Statistical tests.-All statistical tests were conducted in the statistical software package $\mathrm{R}$ version 3.3.1 (R Core Team 2014). We performed a Chi-square test to determine retreat size preference. The results from this test indicated that there were two favorable retreat sizes, medium and large (see Results), which we then used for the social interaction trials. We analyzed propensity of individuals to share retreats using generalized linear mixed modeling (GLMM) techniques. Our response variable (whether spiders shared retreats or not) was modeled with a binomial distribution and logit link function and spider ID as a random effect. We compared a fully parameterized model with individual ID as a random effect to a model without it, while keeping the fixed effect structure, using a likelihood ratio test (1 degree of freedom [df], (Pinheiro \& Bates 2000), to test for significant consistent individual differences in propensity to share retreats. We did not detect any consistent differences among individuals in tendency to share retreats in D. lapidicola (Table 1). To avoid redundancy in our models predicting propensity to share retreats, we continued our analyses using generalized linear models without a random effect.

To determine what factors predicted propensity to share retreats, we utilized an information theoretic approach to discern which variable best predicted the number of retreats shared. The model set included only models with a single main effect. Therefore we had eight models with effects of size, sex, 


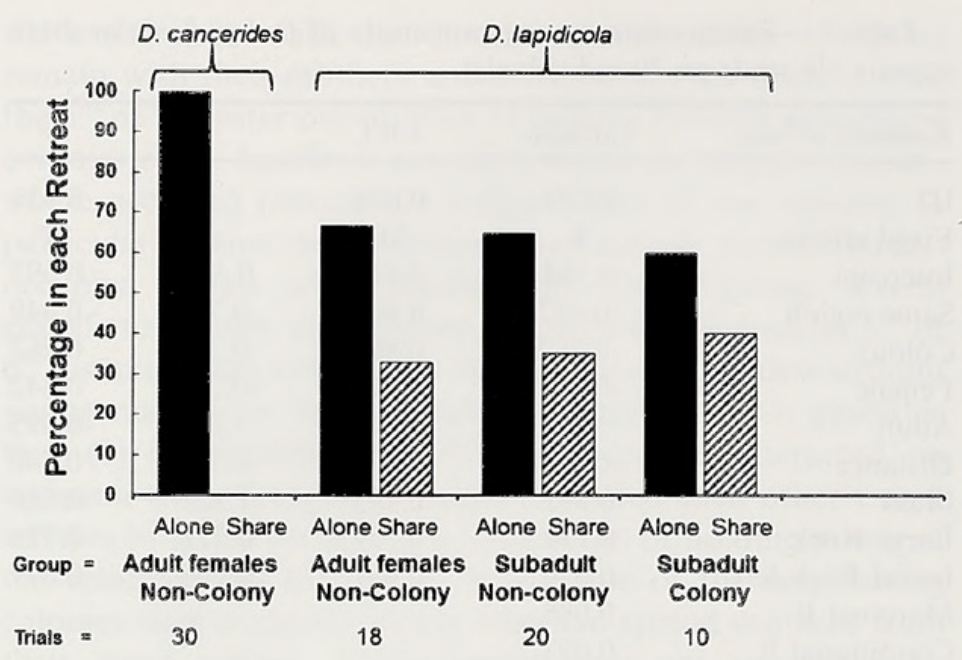

Figure 1.-Percentage of trials where spiders settled into retreats by themselves (Alone) or with the other individual in the experiment (Share) for Delena cancerides and D. lapidicola. Results for $D$. lapidicola trials were separated based on the experimental animals' age-class and whether they came from the same colony or from different colonies (non-colony). There were no significant differences in the percentage of retreats shared and alone in different $D$. lapidicola groups, but $D$. cancerides were alone significantly more than all $D$. lapidicola.

colony distance, whether spiders were from the same colony, size of rocks in trials (medium or large), the retreat (left or right) initially occupied by the resident, whether pairs originated from the same region, and an additional null model.

We also constructed binomial GLMMs to determine how retreat-sharing patterns and aggression differed between adult female $D$. lapidicola and $D$. cancerides. Both aggression and retreat sharing response variables were coded as binomial responses. The model sets included only models with a single fixed effect and individual ID as a random effect. Including the null model, there were 8 models with effects of all size measurements, size of rocks in trials (medium or large), the retreat (left or right) initially occupied, and the species ( $D$. lapidicola or D. cancerides). All GLMMs were fitted using the LME4 package (Bates et al. 2015) and were compared using Akaike's Information Criteria with a small sample size correction $(\mathrm{AICc})$. We also calculated Akaike weight using the BBMLE package (Bolker 2017), $\omega_{i}$, to estimate the probability of one model being the best fit for the data, relative to all other compared models. Models within two $\Delta$ AIC were deemed to have equivalent fits (Burnham \& Anderson 2002).

\section{RESULTS}

Retreat size preference.-When given a choice of retreats of different sizes, D. lapidicola preferred larger retreats over smaller retreats. Medium sized retreats were preferred over small ( $\left.n=10, \chi^{2}=10, \mathrm{df}=1, P=0.002\right)$, and large over small $\left(n=10, \chi^{2}=10, \mathrm{df}=1, P=0.002\right)$. There was no difference in preference between medium and large retreats $\left(n=18, \chi^{2}=\right.$ 2.29, $\mathrm{df}=1, P=0.13$ ).

Retreat sharing in Delena lapidicola.-Forty-two percent of the trials resulted in individuals sharing retreats irrespective of which colony they originated from (Fig. 1). Using a model comparison approach, we did not find any variable that was successful in predicting retreat sharing patterns, as the best fit model was the null, intercept-only model $\left(\omega_{i}=0.295\right.$; Table 2$)$. The second and third best fit models included which retreat (left or right) was initially occupied by the resident and whether spiders in a trial were from the same colony, respectively. However, neither of these models contained a significant effect on propensity to share retreats and only carried a combined $24 \%$ of the total weight. These results imply that among other factors, neither sex, nor age, nor colony, nor distance between colonies of origin influence retreat sharing behavior in $D$. lapidicola.

Retreat sharing in Delena cancerides.-Delena cancerides never shared retreats with conspecifics from other colonies. As such, the best model identified species as the best predictor for sharing retreats, with trials conducted with $D$. cancerides occupying separate retreats $(\triangle \mathrm{AICc}$ to next model $=3.8$, and weight $\omega_{i}=0.8119$; Table 3 ). A likelihood ratio test revealed that there were no individual differences across adult females of either species in propensity to share retreats $\left(X^{2}=0.442\right.$, df $=1, P=0.506$ ).

Rates of conflict.-The levels of aggression in D. lapidicola and $D$. cancerides in social interaction trials was also dramatically different. Only one aggressive encounter occurred in D. lapidicola trials, when a resident adult female attacked and killed the adult female intruder immediately upon introduction. In contrast, 11 of the 30 trials with $D$. cancerides resulted in either lost limbs or mortality. As such, the best-fit model for predicting aggression identified species as the best predictor $\left(\Delta \mathrm{AICc}\right.$ to next model $=29.3$, and weight, $\omega_{i}$ $=1$; Table 4). Furthermore, in trials with aggression in $D$. cancerides, a likelihood ratio test between models with and without individual ID as a random effect revealed amongindividual differences in female aggression $\left(X^{2}=5.82, \mathrm{df}=1\right.$, $P=0.016)$.

Table 2.-Top three generalized linear models for predicting propensity of $D$. lapidicola to share retreats as indicated by AICc model selection procedures. AICc: Akaike's Information Criterion corrected for small sample size; $\omega_{i}$ : Akaike weight.

\begin{tabular}{|c|c|c|c|c|c|c|c|c|c|}
\hline & \multicolumn{3}{|c|}{ Shared Retreats $\sim 1$} & \multicolumn{3}{|c|}{ Shared Retreats $\sim$ Left rock initially occupied } & \multicolumn{3}{|c|}{ Shared Retreats $\sim$ same colony } \\
\hline & $\beta$ & SE & $P$ & $\beta$ & SE & $P$ & $\beta$ & SE & $P$ \\
\hline Intercept & -0.601 & 0.3018 & 0.0465 & -0.319 & 0.4647 & 0.493 & -0.654 & 0.3419 & 0.0558 \\
\hline Initial Occupied Rock & - & - & - & -0.48 & 0.614 & 0.434 & - & - & - \\
\hline Colony & \multicolumn{3}{|c|}{$\begin{array}{c}\mathrm{AICc}=64.399 \\
\omega_{i}=0.295\end{array}$} & \multicolumn{3}{|c|}{$\begin{array}{l}\mathrm{AICc}=65.788 \Delta \mathrm{AICc}=1.6 \omega_{i}=0.134 \\
\mathrm{R}^{2}\end{array}$} & \multicolumn{3}{|c|}{$\begin{array}{l}\mathrm{AICc}=66.284 \Delta \mathrm{AICc}=2.1 \omega_{i}=0.105 \\
\mathrm{R}^{2}{ }_{\mathrm{adj}}=0.002 \text { and } \mathrm{F}_{1,46}=0.11, \mathrm{p}=0.74\end{array}$} \\
\hline
\end{tabular}


Table 3.-The best-fit model predicting propensity of adult females to share retreats in trials conducted with all $D$. cancerides and trials conducted with all $D$. lapidicola as indicated by AICc model selection procedures. AICc: Akaike's Information Criterion corrected for small sample size; $\omega_{i}$ : Akaike weight.

\begin{tabular}{lcccc}
\hline Random effects & Estimate & & & \\
\hline ID & 0.640 & & & \\
Fixed Effects & $\beta$ & SE & $\mathrm{Z}$ & $\mathrm{P}$ \\
Intercept & -21.62 & 211.24 & 16.999 & 0.918 \\
Lapidicola & 20.58 & 211.24 & 3.495 & 0.922 \\
Marginal R ${ }^{2}$ & 0.962 & & & \\
Conditional $\mathrm{R}^{2}$ & 0.968 & & & \\
\hline
\end{tabular}

\section{DISCUSSION}

Our a priori predictions about the propensity of Delena lapidicola to share retreats based on the traits observed in $D$. cancerides were almost uniformly incorrect. When given a choice between sharing retreats and occupying a retreat solitarily, the prolonged subsocial Delena lapidicola shared retreats $42 \%$ of the time regardless of the spider's age, colony, or distance between colonies of origin in our experiments. Notably, the percentage of adult females who shared was similar to that of the other age-classes and non-colony mates pairs. This is particularly surprising considering that adult females were not found sharing any retreats with other adult females in the wild (field data 2008 and 2014: $n=26$ rock retreats that had an adult female plus other individuals, Rayor, unpublished data). Moreover, with the exception of a single mortality event between adult females, there was no evidence of aggression between these spiders in our experiments. None of the adult females we used in this experiment were on the verge of laying eggs, so more aggression might be anticipated by those females. This level of tolerance and tendency to aggregate in $D$. lapidicola was completely unexpected.

The most probable explanation for our observations of frequent retreat sharing and the lack of aggression in $D$. lapidicola is that there may be limited selection for active defense of rock retreats. The natural rock retreats for $D$. lapidicola are relatively abundant, with the number of potential retreats vastly exceeding the number of colonies in the habitat (Rayor 2016). Even minor shifts in the positions of rock retreats dramatically impact acceptability to reptiles for retreats on rock outcrops (Croak et al. 2008), so our assessment of abundance of suitable retreats may be an overestimate but there were likely more potential retreats than spiders in all areas. Most $D$. lapidicola do not lay down silk or put other investment into improving the rock retreat, with the exception of adult females that put down silk bands around their egg sacs to protect from predators and parasites. Therefore, because the retreats are apparently plentiful and require little investment, their low value likely reduces the need for defense from other individuals. Simultaneously, tolerance toward conspecifics may be beneficial because social aggregations of marbled geckos (Christinus marmoratus), which appear to be both predators and prey of the spiders, are potential competitors for the same retreat rocks (Kearney et al. 2001; Rayor unpublished
Table 4.-The best-fit model predicting aggression within adult females in trials conducted with all $D$. cancerides and trials conducted with all $D$. lapidicola as indicated by AICc model selection procedures. AICc: Akaike's Information Criterion corrected for small sample size; $\omega_{i}$ : Akaike weight.

\begin{tabular}{lcccc}
\hline Random effects & Estimate & & & \\
\hline ID & 0.640 & & & \\
Fixed Effects & $\beta$ & SE & Z & P \\
Intercept & 71.38 & 713.04 & 0.100 & 0.920 \\
Lapidicola & -85.93 & 714.04 & -0.121 & 0.904 \\
Marginal R ${ }^{2}$ & 0.124 & & & \\
Conditional $\mathrm{R}^{2}$ & 0.999 & & & \\
\hline
\end{tabular}

data). Thus, our data suggest that with more abundant retreat options, $D$. lapidicola more closely fit the situation where individuals more readily share retreats because there are few benefits to defending the retreat and potential benefits to sharing.

In contrast, Delena cancerides adult females never shared retreats and serious aggression was commonplace, aligning with previous studies suggesting that rare retreats require active defense, particularly for females who need sole ownership of a retreat to reproduce. In $D$. cancerides conspecific competition for retreats is intense, the retreats require active effort to securely attach the bark to the tree, and the spiders are intolerant and aggressive toward unrelated conspecifics (Yip et al. 2009, 2012). This environmental constraint of a limited number of available retreats is hypothesized to drive selection for sociality within $D$. cancerides, with offspring remaining in their natal colony with their mother until they are physically able to compete for rare retreats. The contrast between $D$. lapidicola and $D$. cancerides social tolerance and willingness to share retreats is an illustration of how differences in retreat availability and investment in maintaining the retreat may influence social dynamics in social spiders.

Social factors must influence retreat sharing decisions in these prolonged subsocial spiders, but our results do not demonstrate whether or not kin recognition is found in $D$. lapidicola. There is strong evidence of kin discrimination in $D$. cancerides and other subsocial species where spiders respond to kin and non-kin differentially based on chemosensory cues, even if the spiders are familiar with non-kin (Beavis et al. 2007; Schneider \& Bilde 2008; Grinsted et al. 2011; but see Auletta \& Rayor 2011). In this study, we assessed whether retreat sharing with non-colony members exhibited a neighborhood effect, with rock-sharing occurring more frequently between $D$. lapidicola from colonies of origin in proximity $(<50 \mathrm{~m})$ with one another. Distance between colonies had no effect on spiders' propensity to share retreats, with sharing occurring even between spiders from distant granite headlands. Further investigation will be needed to determine whether $D$. lapidicola are capable of discriminating kin or colony mates, or whether their tendency to aggregate in retreats makes kin recognition unimportant. Differences in retreat availability in their native habitat appear to drive the two sister spider species' response to retreat sharing. 


\section{ACKNOWLEDGMENTS}

We greatly appreciated the assistance of Francesca $T$. van den Berg (University of Sydney/ Macquarie University), Jacob Hurst (Cornell, Fresno State University), Two-People's Bay Ranger Mark True, and Dr. Mark Harvey (Western Australia Museum) in collecting and studying the field biology of $D$. lapidicola. Francesca van den Berg, Eric Yip, Cole Gilbert, Orr Spiegel and anonymous reviewers provided invaluable input on the manuscript. Financial support was provided by Hunter Rawlings Cornell Presidential Research Scholars of Cornell University for Cameron Jones.

\section{LITERATURE CITED}

Agnarsson, I. \& L.S. Rayor. 2013. A molecular phylogeny of the Australian huntsman spiders (Sparassidae, Deleninae): Implications for taxonomy and social behavior. Molecular Phylogenetics and Evolution 69:895-905.

Auletta, A. \& L.S. Rayor. 2011. Preferential prey sharing among kin not found in the social huntsman spider, Delena cancerides (Sparassidae). Journal of Arachnology 39:258-262.

Bates, D., M. Mächler, B. Bolker \& S. Walker. 2015. Fitting linear mixed-effects models using lme4. Journal of Statistical Software 67:1.

Beavis, A.S., D.M. Rowell \& T. Evans. 2007. Cannibalism and kin recognition in Delena cancerides (Araneae: Sparassidae), a social huntsman spider. Journal of Zoology 271:233-237.

Berger-Tal, R., Y. Lubin, V. Settepani, M. Majer, T. Bilde \& C. Tuni. 2015. Evidence for loss of nepotism in the evolution of permanent sociality. Scientific Reports 5:13284.

Berryman, A. \& B. Hawkins. 2006. The refuge as an integrating concept in ecology and evolution. Oikos 115:192-196.

Bilde, T. \& Y. Lubin. 2001. Kin recognition and cannibalism in a subsocial spider. Journal of Evolutionary Biology 14:959-966.

Bolker, B. 2017. Tools for General Maximum Likelihood Estimation. Online at https://cran.r-project.org/web/packages/bbmle/bbmle. pdf

Burnham, K. \& D. Anderson. 2002. Model Selection and Multimodel Inference: A Practical Information-Theoretic Approach. Springer, New York.

Croak, B., D. Pike, J. Webb \& R. Shine. 2008. Three-dimensional crevice structure affects retreat site selection by reptiles. Animal Behaviour 76:1875-1884.

Croak, B., D. Pike, J. Webb \& R. Shine. 2012. Habitat selection in a rocky landscape: Experimentally decoupling a retreat site attributes from that of landscape features. PloS ONE 7(6):e37982.

Dubey, S., B. Croak, D. Pike, J. Webb \& R. Shine. 2012. Phylogeography and dispersal in the velvet gecko (Oedura lesueurii), and potential implications for conservation of an endangered snake (Hoplocephalus bungaroides). BMC Evolutionary Biology 12:67.
Dubey, S., J. Sumner, D. Pike, J.S. Keogh, J. Webb \& R. Shine. 2011. Genetic connectivity among populations of an endangered snake species from Southeastern Australia (Hoplocephalus bungaroides, Elapidae). Ecology and Evolution 1:218-227.

Evans, T.A. 1999. Kin recognition in a social spider. Proceedings of the Royal Society of London B: Biological Sciences 266:287-292.

Goldsbrough, C., D. Hochuli \& R. Shine. 2004. Fitness benefits of retreat-site selection: Spiders, rocks, and thermal cues. Ecology $85: 1635-1641$

Grinsted, L., T. Bilde \& P. d'Ettorre, 2011. Cuticular hydrocarbons as potential kin recognition cues in a subsocial spider. Behavioral Ecology 22:1187-1194.

Huey, R., C. Peterson, S. Arnold \& W. Porter. 1989. Hot rocks and not-so-hot rocks: retreat-site selection by garter snakes and its thermal consequences. Ecology 70:931-944.

Kearney, M., R. Shine, S. Comber \& D. Pearson. 2001. Why do geckos group? An analysis of "social" aggregations in two species of Australian lizards. Herpetologica 57:411-422.

Langkilde, T. \& R. Shine. 2004. Competing for crevices: interspecific conflict influences retreat- site selection in montane lizards. Oecologia 140:684 691.

Pike, D., J. Webb \& R. Andrews. 2011. Social and thermal cues influence nest-site selection in a nocturnal gecko, Oedura lesueurii. Ethology 117:796-801.

Pinheiro, J. \& D. Bates 2000. Mixed-Effects Models in S and S-PLUS. Springer Science and Business Media.

R Core Team 2014. R: A language and environment for statistical computing. R Foundation for Statistical Computing, Vienna, Austria. Online at http://www.R-project.org/

Rayor, L.S. 2016. How habitat and retreat limitation influence sociality in prolonged subsocial spiders. Denver Museum of Nature \& Science Reports 3:158-159.

Ruch, J., M. Dumke \& J.M. Schneider. 2015. Social network structure in group-feeding spiders. Behavioral Ecology and Sociobiology 69:1429-1436.

Schneider, J. \& T. Bilde 2008. Benefits of cooperation with genetic kin in a subsocial spider. Proceedings of the National Academy of Sciences USA 105:10843-10846.

Yip, E.C. \& L.S. Rayor. 2011. Do social spiders cooperate in predator defense and foraging without a web? Behavioral Ecology and Sociobiology 65:1937-1945.

Yip, E.C. \& L.S. Rayor. 2014. Maternal care and subsocial behavior in spiders. Biological Reviews 89:427-449.

Yip, E.C., S. Clarke \& L.S. Rayor. 2009. Aliens among us: Nestmate recognition in the social huntsman spider, Delena cancerides. Insectes Sociaux 56:223-231.

Yip, E.C., D.M. Rowell \& L.S. Rayor. 2012. Behavioral and molecular evidence for selective immigration and group regulation in the social huntsman spider, Delena cancerides (Araneae: Sparassidae). Biological Journal of the Linnean Society 106:749 762.

Manuscript received 30 September 2016, revised 11 August 2017. 


\section{$2 \mathrm{BHL}$ Biodiversity Heritage Library}

Jones, Cameron and Rayor, Linda S. 2017. "Retreat availability and social influences on retreat sharing in group-living huntsman spiders, Delena lapidicola and Delena cancerides (Araneae: Sparassidae)." The Journal of arachnology 45(3), 271-276. https://doi.org/10.1636/joa-s-16-069.1.

View This Item Online: https://www.biodiversitylibrary.org/item/274724

DOI: https://doi.org/10.1636/joa-s-16-069.1

Permalink: https://www.biodiversitylibrary.org/partpdf/289912

\section{Holding Institution}

Smithsonian Libraries

\section{Sponsored by}

Biodiversity Heritage Library

\section{Copyright \& Reuse}

Copyright Status: In Copyright. Digitized with the permission of the rights holder

Rights Holder: American Arachnological Society

License: https://creativecommons.org/licenses/by-nc-sa/4.0/

Rights: http://www.biodiversitylibrary.org/permissions/

This document was created from content at the Biodiversity Heritage Library, the world's largest open access digital library for biodiversity literature and archives. Visit BHL at https://www.biodiversitylibrary.org. 